\title{
Extrinsic and idiopathic vernal keratoconjunctivitis? Two cases with dissimilar immunopathology
}

\author{
A. ZAVARO, ${ }^{1}$ Y. R. BARYISHAK, ${ }^{1} \mathrm{Z}$. SAMRA ${ }^{2}$ AND D. SOMPOLINSKY ${ }^{2}{ }^{3}$ \\ From the Departments of ${ }^{1}$ Ophthalmology and ${ }^{2}$ Microbiology, Assaf Harofe Hospital, Zerifin, and \\ ${ }^{3}$ Rappaport Laboratories of Microbiology, Bar-Ilan University, Israel.
}

SUMmARY Two clinically similar cases of vernal keratoconjunctivitis with dissimilar immunological data are reported. One patient had strikingly elevated IgE levels in both serum and tears, and his tear fluid contained specific IgE antibodies to a number of allergens. Conjunctival scrapings and peripheral blood samples showed marked eosinophilic reactions. The other patient showed normal values for tear and serum IgE; no IgE type antibodies to allergens were detected; and no local or systemic eosinophilic reactions were observed. The immunopathogenesis of these cases is discussed.

Vernal keratoconjunctivitis (VKC) is an inflammatory disorder of the conjunctival mucosa. The main symptoms are itching, photophobia, intense tearing, and a mucoid discharge that may stick the eyelashes together in bundles. On examination the most characteristic and persistent feature is a papillary hypertrophy of the upper tarsal conjunctiva ('cobblestones'). The cornea may be involved to varying degrees from a superficial punctate keratitis to indolent corneal ulceration.

The disorder is usually considered of allergic aetiology with mainly IgE intervention. ${ }^{1}$ Elevated levels of $\mathrm{IgE}$ in serum and tears of the patients have been reported, ${ }^{23}$ and conjunctival scrapings reveal usually a considerable number of eosinophilic leucocytes.

In Israel the disease is endemic, with onset in early childhood, and often the symptoms fade and disappear towards adolescence. Most of the patients show strikingly increased tear IgE, but in more than $20 \%$ IgE levels are persistently normal. ${ }^{3}$ We describe here one patient of each of these groups.

\section{Case reports}

CASE 1

The patient was a boy born in 1975. As an infant he suffered from spastic bronchitis. Since 1977 he had been treated for VKC, initially with dexamethasone and hydrocortisone-neomycin ointment. In June 1979 Correspondence to Professor D. Sompolinsky, Assaf Harofe Hospital, Zerifin 70300, Israel. he was admitted to hospital with a serious aggravation -itching, severe photophobia, tearing, and red eyes. On examination he had hyperaemic sloppy conjunctivae, giant papillary hypertrophy of the upper tarsus, severe superficial keratitis with an area of considerable epithelial loss (right eye), and thick mucous discharge; the right eye seemed more seriously attacked than the left. Treatment with $2 \%$ sodium cromoglycate 4 times a day, and, when needed, $20 \%$ acetylcystein, apparently had a beneficial effect. Since then the patient has had persistent low-grade inflammation with 3 episodes of moderate aggravation, always more severe in the right than the left eye (December 1981, November 1982, May 1983).

CASE 2

The patient was a boy born in 1970 . He had a history of spastic bronchitis and frequent rhinitis during 1972-6, and presented at the clinic in 1981 owing to prolonged complaints of itching, photophobia, excess tearing, and red eyes. On examination he had wet, hyperaemic eyes, with prominent papillary hypertrophy of the upper tarsal conjunctivae ('cobblestones') and ropy mucoid discharge. There was partial ptosis of both eyes, with superficial keratitis of the right and corneal ulceration of the left eye $(1 \times 2 \mathrm{~mm})$. The giant papillae were treated with cryotherapy in addition to topical antibiotics, corticosteroids, and $2 \%$ sodium cromoglycate. The ulcer healed slowly. The boy was observed and treated in our clinic for 18 months. 
Table 1 Prick tests to allergens (size of the induration zones ( $\mathrm{mm}$ ) after $15 \mathrm{~min})$

\begin{tabular}{lll}
\hline Allergen & Case 1 & Case 2 \\
\hline House mite & $9 \times 7$ & 0 \\
House dust & $5 \times 5$ & 0 \\
Cat fur & $4 \times 5$ & $3 \times 3$ \\
Dog hair & $4 \times 4$ & 0 \\
Weed pollen & $5 \times 5$ & 0 \\
Chicken feathers & 0 & $2 \times 2$ \\
Aspergillus fumigatus & 0 & $4 \times 4$ \\
Milk, whole egg, grass pollen, & & \\
$\quad$ Penicillium notatum & 0 & 0 \\
Histamine (control) & $7 \times 8$ & $9 \cdot 5 \times 10 \cdot 5$ \\
\hline
\end{tabular}

LABORATORY INVESTIGATIONS

Blood and tear samples were obtained periodically. The tear fluid was collected in microtubes from the lower fornix. ${ }^{4}$ From case 1, 9 blood samples and 16 tear samples from the right and 14 from the left eye were examined during 3 years. From case 2, 7 blood samples and 7 tear samples from each eye were collected during a period of $1 \frac{1 / 2}{2}$ years.

Serum albumin (HSA) was assayed by radial immunodiffusion. ${ }^{4}$ Tear and serum IgE levels were determined by solid-phase radioimmunoassay (PRIST, Pharmacia Ltd, Uppsala, Sweden). The limit for sensitivity was $0.5 \mathrm{IU} / \mathrm{ml}$. Specific IgE antibodies to a series of allergens were assayed by the radioallergosorbent technique (RAST, Pharmacia Ltd). Results are expressed as percentage of radioactivity obtained with the commercial $\mathbf{A}$ grade standard $(=100 \%)$. Fetal calf serum and serum from human cord blood were used as negative controls (2.0-4.5\% of $A$ grade).

Conjunctival scrapings and peripheral blood smears were stained with Giemsa's stain. Prick testing of the skin was performed with a set of 11 allergen extracts (Bencard Ltd, Brentford, UK).

\section{Results}

Prick tests. Table 1 shows that both patients reacted to a number of allergen extracts.
Eosinophilic leucocytes. For case 1 an increased number of eosinophils were demonstrated in conjunctival scrapings and peripheral blood (total leucocytes $\left.=11-13 \times 10^{9} / 1\right)$. In case 2 no eosinophilic leucocytes could be demonstrated in conjunctival scrapings, and 1-2\% of leucocytes of the blood were eosinophils.

Tear HSA. The mean of tear HSA was for case 1 $253 \cdot 5 \pm 159 \cdot 8$ ( \pm SD) and for case $2409 \cdot 1 \pm 459 \cdot 3$ $\mathrm{mg} / \mathrm{dl}$ (Table 2 ). Tears from healthy controls contain $17 \cdot 7 \pm 12 \cdot 6 \mathrm{mg} / \mathrm{dl} \mathrm{HSA} .^{4}$ (SI conversion: $\mathrm{mg} / \mathrm{dl} \times 10=$ $\mathrm{mg} / \mathrm{l}$.)

Tear and serum $\operatorname{IgE}$. The geometrical mean (GM) of serum IgE was 990.1 for case 1 and $10.9 \mathrm{IU} / \mathrm{ml}$ for case 2 (Table 2). GM for tear IgE for case 1 was $127 \cdot 4$ $\mathrm{IU} / \mathrm{ml}$ for the right and $93.8 \mathrm{IU} / \mathrm{ml}$ for the left eye, but in tears from case 2 we could never demonstrate $\operatorname{IgE}(<0.5 \mathrm{IU} / \mathrm{ml})$.

Specific IgE type antibodies. Table 3 shows the results of RAST for 17 allergens. The limit for a positive reaction was arbitrarily set at $10 \%$, approximately the level obtained with the $\mathrm{D}$ grade standard. Tears of case 1 reacted with house mites and house dust, the 2 grasses, 2 moulds, and chicken feathers. The examinations were performed with serum samples which contained several times more IgE than the corresponding tear samples; in spite of this none of the above reactions were stronger with serum than with tears, and several were significantly weaker. Positive reactions were also obtained with the serum, but not with tears, to 2 food allergens (egg white and wheat).

With tears and serum from case 2 no significant reactions to any of the tested allergens were obtained.

\section{Discussion}

The 2 cases described are representative of 2 groups of VKC patients with dissimilar immunological data. About $80 \%$ of patients in our care show elevated tear IgE $\left(>10 \mathrm{IU} / \mathrm{ml}\right.$ and sometimes even $\left.>1000 \mathrm{IU} / \mathrm{ml}^{3}\right)$ and marked eosinophilic reaction in the conjunctival

Table 2 Two cases of vernal keratoconjunctivitis

\begin{tabular}{|c|c|c|c|c|c|c|c|c|}
\hline & \multicolumn{2}{|l|}{ Eosinophils } & \multirow{4}{*}{$\begin{array}{l}\text { Tear } H S A \\
(m g / d l) \\
\text { Mean }( \pm S D)\end{array}$} & \multicolumn{5}{|l|}{$\operatorname{IgE}(I U / m l)$} \\
\hline & \multirow{3}{*}{$\begin{array}{l}\text { Conjunctival } \\
\text { scraping } \\
\text { per } H P F\end{array}$} & \multirow{3}{*}{$\begin{array}{l}\text { Blood } \\
\text { \% of } W B C\end{array}$} & & \multicolumn{2}{|l|}{ Serum } & \multicolumn{3}{|l|}{ Tears } \\
\hline & & & & \multirow[t]{2}{*}{$G M(+1 S D)$} & \multirow[t]{2}{*}{ Range } & \multicolumn{2}{|l|}{$G M(+1 S D)$} & \multirow[t]{2}{*}{ Range } \\
\hline & & & & & & $O D$ & $O S$ & \\
\hline $\begin{array}{l}\text { Case } 1 \\
\text { Case } 2\end{array}$ & $\begin{array}{l}1-2 \\
0\end{array}$ & $\begin{array}{c}11-24 \\
1-2\end{array}$ & $\begin{array}{l}253 \cdot 5( \pm 159 \cdot 8) \\
409 \cdot 1( \pm 459 \cdot 3)\end{array}$ & $\begin{array}{c}990.1(1390.3) \\
10.9(26.4)\end{array}$ & $\begin{array}{c}620 \cdot 0-1575 \cdot 0 \\
2 \cdot 5-31 \cdot 5\end{array}$ & $\begin{array}{l}127 \cdot 4(292 \cdot 5) \\
\quad<0 \cdot 5\end{array}$ & $\begin{array}{l}93.8(212.9) \\
<0.5\end{array}$ & $\begin{array}{l}14 \cdot 8-580 \cdot 0 \\
<0.5\end{array}$ \\
\hline
\end{tabular}

$\mathrm{HPF}=$ high-power field. $\mathrm{WBC}=$ white blood cells. $\mathrm{OD}=$ right eye. $\mathrm{OS}=$ left eye. $\mathrm{GM}=$ geometric mean. Mean tear $\mathrm{HSA}$ of tears from healthy eyes was $17.7 \mathrm{mg} / \mathrm{dl} .{ }^{4} \mathrm{GM}$ of tear IgE from healthy eyes was $0.92 \mathrm{IU} / \mathrm{ml}$, and the highest level of tear IgE observed among the healthy controls was $6.6 \mathrm{IU} / \mathrm{ml}^{3}{ }^{3}$ (SI conversion: $\mathrm{mg} / \mathrm{dl} \times 10=\mathrm{mg} / \mathrm{l}$.) 
Table 3 Specific IgE antibodies (\%) of tears (T) and serum (S)

\begin{tabular}{|c|c|c|c|c|c|c|}
\hline \multicolumn{2}{|c|}{ Allergens } & \multicolumn{3}{|l|}{ Case 1} & \multicolumn{2}{|c|}{ Case 2} \\
\hline & & $T$ & $S$ & $T / S$ & $T$ & $S$ \\
\hline 1 & Dermatophagoides (house mites) & $124 \cdot 5$ & $124 \cdot 8$ & $1 \cdot 00$ & $3 \cdot 7$ & $4 \cdot 2$ \\
\hline 2 & House dust & $66 \cdot 9$ & $78 \cdot 5$ & $0 \cdot 85$ & $4 \cdot 1$ & $4 \cdot 6$ \\
\hline 3 & Cat epithelium & $7 \cdot 1$ & $5 \cdot 4$ & & $4 \cdot 6$ & $4 \cdot 1$ \\
\hline 4 & Dog epithelium & $6 \cdot 0$ & $5 \cdot 7$ & & $5 \cdot 1$ & $5 \cdot 3$ \\
\hline 5 & Blatella germanica (cockroach) & $7 \cdot 6$ & $9 \cdot 1$ & & $1 \cdot 8$ & $2 \cdot 7$ \\
\hline 6 & Vernal grass & $12 \cdot 6$ & $8 \cdot 1$ & & $3 \cdot 0$ & $3 \cdot 4$ \\
\hline 7 & Bermuda grass & $51 \cdot 0$ & $22 \cdot 8$ & $2 \cdot 24$ & $4 \cdot 3$ & $4 \cdot 5$ \\
\hline 8 & Cladosporium herbarum & $21 \cdot 1$ & $16 \cdot 8$ & $1 \cdot 26$ & $4 \cdot 7$ & $5 \cdot 2$ \\
\hline 9 & Olive & $9 \cdot 8$ & $3 \cdot 7$ & & $2 \cdot 6$ & $2 \cdot 5$ \\
\hline 10 & Egg white & $5 \cdot 3$ & $12 \cdot 5$ & & $3 \cdot 5$ & $4 \cdot 3$ \\
\hline 11 & Wheat & $8 \cdot 1$ & $15 \cdot 8$ & & 4.9 & 5.9 \\
\hline 12 & Orange & $4 \cdot 0$ & $9 \cdot 3$ & & $2 \cdot 6$ & $2 \cdot 7$ \\
\hline 13 & Milk (cow) & 4.9 & $5 \cdot 0$ & & $4 \cdot 5$ & 4.9 \\
\hline 14 & Ambrosia elatior & $3 \cdot 4$ & $6 \cdot 5$ & & $3 \cdot 3$ & $3 \cdot 5$ \\
\hline 15 & Mucor racemosus & $18 \cdot 8$ & $8 \cdot 8$ & & $4 \cdot 0$ & $3 \cdot 7$ \\
\hline 16 & Chicken feathers & $41 \cdot 2$ & $24 \cdot 2$ & $1 \cdot 70$ & $3 \cdot 5$ & $3 \cdot 6$ \\
\hline 17 & Fish & $3 \cdot 4$ & $3 \cdot 8$ & & $1 \cdot 7$ & $2 \cdot 0$ \\
\hline
\end{tabular}

Specific IgE values are indicated as a percentage of radioactivity obtained with the standard A of the RAST kit. For human cord serum and fetal calf serum $2 \cdot 0-4 \cdot 4 \%$ were obtained with all allergens.

The examinations of case 1 were performed with different specimens of tears (both eyes) and serum collected on the same day. For allergens 1-9 the total IgE content was: $\mathrm{T}=285 \mathrm{IU} / \mathrm{ml} ; \mathrm{S}=950 \mathrm{IU} / \mathrm{ml} ; \mathrm{T} / \mathrm{S}=0 \cdot 30$. For allergens $10-14: \mathrm{T}=73 \mathrm{IU} / \mathrm{ml} ; \mathrm{S}=645 \mathrm{IU} / \mathrm{ml} ; \mathrm{T} / \mathrm{S}=0 \cdot 11$. For allergens $15-17: \mathrm{T}=364 \mathrm{IU} / \mathrm{ml} ; \mathrm{S}=1065 \mathrm{IU} / \mathrm{ml}: \mathrm{T} / \mathrm{S}=0 \cdot 34$. For case 2 pools of tears containing $<0 \cdot 5 \mathrm{IU} / \mathrm{ml}$ and serum containing $17 \cdot 7 \mathrm{IU} / \mathrm{ml}$ were used.

tissue, whereas about $20 \%$ of the patients show persistently normal tear IgE levels (see footnote, Table 2) and lack of eosinophilic reactions. Clinically we cannot distinguish between these groups. The 2 cases reported here were both typical for VKC. Case 2 was complicated by corneal ulceration, an infrequent sequela of epithelial damage, and his tear HSA levels were higher than for case 1 (Table 2). Tear HSA is a measure of vascular leakage but depends also on the tear flow.

Patients with bronchial asthma are usually divided into groups with high and low serum IgE ('extrinsic' and idiopathic ('intrinsic') respectively). ${ }^{5}$ However, in asthma patients it is usually not possible to assess the levels of $\mathrm{IgE}$ in the local secretion in a way comparable to the tear examinations. As possible causes of idiopathic asthma autoantibodies to IgE receptors or to IgE type immunoglobulin have been proposed.$^{67}$ These hypotheses might be proposed for low IgE VKC, but further studies are needed to verify them. It is of interest that in spite of the persistently low serum and tear IgE case 2 showed some moderately positive prick tests; however, none of the RAST examinations revealed specific IgE antibodies in serum and tears.

For case 1 some (but not all) of the positive prick tests were confirmed by the RAST technique. It is of interest that for allergens for which both serum and tears were positive $>10 \%$ in RAST (house mites, house dust, Bermuda grass, Cladosporium herbarum, and chicken feathers) the tear/serum ratio for the strength of the RAST reaction exceeded by far the corresponding ratio for total IgE. It has been demonstrated that assays of the RAST type are not strictly quantitative. ${ }^{8}$ In spite of this the results shown in Table 3 for case 1 seem impressive. Serum samples which contained 3 times more IgE than the corresponding tear samples reacted only equally to or mich more weakly than the tear samples with several of the allergens, although the assays were performed simultaneously and with the same batch of allergen discs. This may indicate that the tear $\operatorname{IgE}$ antibodies were essentially a product of local synthesis. ${ }^{9}$ Pollenspecific antibodies of the IgE type have been demonstrated by others in tears of VKC patients, ${ }^{1011}$ but these authors did not look for IgE antibodies to other common allergens. Our results indicate that common allergens of wide ecological distribution may sensitise the tissue of the outer eye.

We acknowledge financial support for this study from the Medical Research Fund of the Israeli Ministry of Health and the Research Committee of Bar Ilan University, Ramat Gan. The technical help of Mrs Zirel Leizerowitz is appreciated.

\section{References}

1 Jones, BR. Allergic disease of the outer eye. Trans Ophthalmol Soc UK 1971; 91: 441-7.

2 Allansmith MR, Hahn GS, Simon MA. Tissue, tear and serum IgE concentrations in vernal conjunctivitis. Am J Ophthalmol 1976; 81: 506-11. 
3 Baryishak YR, Zavaro A, Monselise M, Samra Z, Sompolinsky D. Vernal keratoconjunctivitis in an Israeli group of patients and its treatment with sodium cromoglycate. Br J Ophthalmol 1982; 66: $118-22$.

4 Zavaro A, Samra Z, Baryishak R, Sompolinsky D. Proteins in tears from healthy and diseased eyes. Doc Ophthalmol 1980; 50: 185-99.

5 Kulczycki Jr A. Role of immunoglobulin E and immunoglobulin E receptors in bronchial asthma. J Allergy Clin Immunol 1981; 68: 5-14.

6 Ishizaka T, Ishizaka K, Conrad DH, Froese A. A new concept of triggering mechanism of IgE-mediated histamine release. $J$ Allergy Clin Immunol 1978; 61: 320-30.
7 Ishizaka T, Ishizaka K. Immune mechanisms of reversed type reaginic hypersensitivity. J Immunol 1969; 103: 588-95.

8 Homburger HA, Jacob GL. Analytic accuracy of specific immunoglobulin $\mathrm{E}$ antibody results determined by a blind proficiency survey. J Allergy Clin Immunol 1982; 70: 474-80.

9 Platts-Mills I. Local production of IgG, IgA and IgE antibodies in grass pollen hay fever. J Immunol 1979; 122: 2218-25.

10 Allansmith M, Frick OL. Antibodies to grass in vernal conjunctivitis. J Allergy 1963; 34: 535-41.

11 Ballow M, Mendelson L. Specific immunoglobulin E antibodies in tear secretions of patients with vernal conjunctivitis. J Allergy Clin Immunol 1980; 66: 112-8. 